\title{
Quantification of Resveratrol in Different Parts of Solid Pinotage Winery Waste: Investigating the Variance Between Consecutive Harvests
}

C. Kriel, R.W.M. Pott*

Department of Process Engineering, Stellenbosch University, C/O Banghoek \& Bosman Road, Stellenbosch, 7600, South Africa

Submitted for publication: February 2020

Accepted for publication: March 2020

Key words: Pinotage, phenolics, resveratrol, solid winery waste

\begin{abstract}
Resveratrol is phenolic compound that is produced by several plant species as a protection mechanism against biotic and abiotic stress. Resveratrol is currently being investigated as nutraceutical supplement, and there is a market value for the compound. The aim of this work was to investigate, through consecutive harvests the variability of solid winery waste as a source of resveratrol as an antioxidant supplement. In this study the different parts of Pinotage solid winery waste from a 2018 and 2019 harvests were investigated as a possible resveratrol source. From the comparison of the different sources over time it was found that the 2019 Pinotage stems contained a maximum of $73 \pm 4.3 \mu \mathrm{g} / \mathrm{g}$ resveratrol. Variable resveratrol concentrations were noted between consecutive harvests, indicating a variability in productivity. Furthermore, resveratrol distribution throughout the plant was variable, with the canes and stems having the highest concentrations. Nonetheless, it was concluded that Pinotage solid winery waste can be used as a possible source of resveratrol. The findings in this paper provide information about the extractable resveratrol and total phenolic content of different parts of Pinotage solid winery waste and the variability of resveratrol content both within the plant, and between harvests.
\end{abstract}

\section{INTRODUCTION}

Resveratrol (3, 5, 4'- Trihydroxy-trans-stilbene) is a stilbenoid produced by plant species in response to injury or when the plant is under attack by fungi or bacteria, and as a mechanism to control environmental stress and is classified as a phytoalexin. Resveratrol is produced as protection against plant pathogens such as Botrytis cinerea and Plasmopara viticola found on Vitis vinifera (Romero-Pérez et al., 2001). Interest in trans-resveratrol as a human supplement arose from the 'French Paradox', where the French population consumes food high in saturated fats together with red wine, while the population has a low cardiovascular diseases expected rate (Romero-Pérez et al., 2001).

Resveratrol is produced in grape skins and some of this solubilizes into red wine during fermentation (Pezet \& Cuenat, 1996). According to Vincenzi et al., (2013) the concentration of resveratrol in red wine is too low for therapeutic effect. This led to the investigation of resveratrol as a nutraceutical supplement at increased doses. The price of resveratrol to be used as nutraceutical supplement, has correspondingly increased, opening up the possibility of producing a resveratrol-based product from grape solid winery waste.

Viticulture is one of the largest agricultural activities in the world (Roca, 2019), with most of the grapes produced used for wine production (Roca, 2019). According to the International Organisation of Vine and Wine (OIV), 292 million hectolitres of wine was produced in 2019 worldwide, with an approximate value of $€ 31$ billion per year; the industry is a significant one.

During the winemaking process, various waste streams are produced - these include grape skins, seeds, and stems, as well as canes and leaves left in the field. Various industries and processes already exist which utilise these wastes to produce valuable compounds such as tartaric acid and grape seed oil, some of which are summarised in Fig. 1.

There have been some studies on the resveratrol content of various parts of solid winery waste. These wastes may be a source of both resveratrol, and other phenolic compounds, for use in nutraceutical production (Devesa-Rey et al., 2011; Beres et al., 2017). However, there has been limited research regarding the distribution of phenolic compounds within a single vine, or how the chemical composition changes between vintages (harvests). How resveratrol varies between years is an important parameter, if one's goal is to produce resveratrol supplements as an additional product using these biomass sources. 


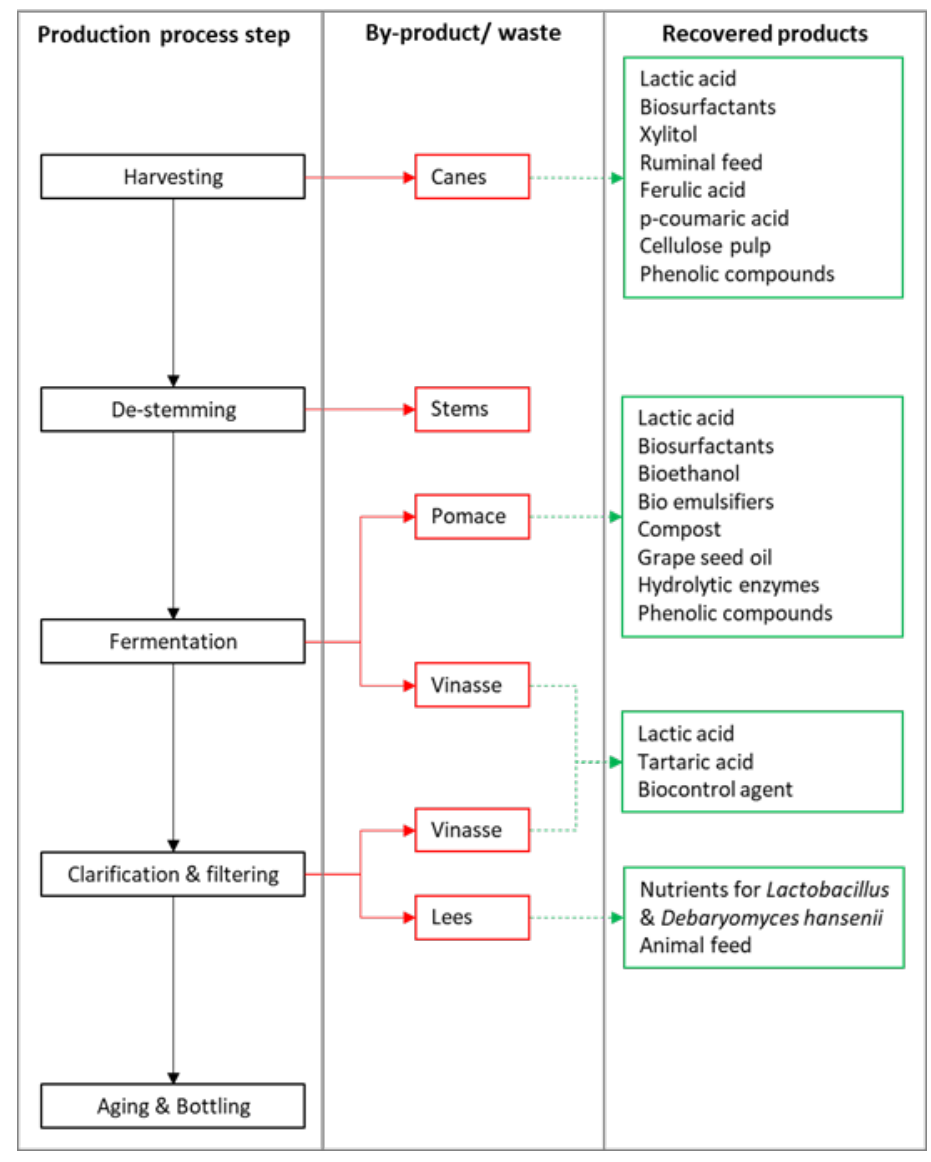

FIGURE 1

Basic illustration of a wine making procedure with the different waste streams (red) and valorised products (green).

Pinotage is a red grape variety that originated in South Africa which is a cross between Cinsaut and Pinot noir (Marais, 2003). Pinotage was created at Stellenbosch University's Welgevallen Experimental farm with the organoleptic characteristics of Pinot noir and the growth characteristics of the robust Cinsaut. Pinotage is generally resistant to powdery mildew and can yield between 10 to 15 tonnes per hectare. Even though 4.7 million litres of Pinotage wine was produced in the 2018 vintage, limited information about the resveratrol content and distribution is available (Marais, 2003), specifically with regards to the solid waste produced during winemaking.

In order to compare the resveratrol and total phenolic content in the different parts of the vine, the resveratrol and other phenolics should be extracted. Solid liquid extraction techniques using organic solvents are usually used for phenolic extractions from plant material (Karacabey \& Mazza, 2008). These solvents can include ethyl acetate, ethanol, methanol and acetone (Geana et al., 2015). Solvent extraction is also a simple method to extract resveratrol from solid biomass. Romero-Pérez et al., (2001) investigated the effectiveness of ethanol-water (80:20 v/v \%), absolute ethanol, ethyl acetate-methanol $(50: 50 \mathrm{v} / \mathrm{v} \%)$, acetonewater $(75: 25 \mathrm{v} / \mathrm{v} \%)$ and $100 \%$ acetone for the extraction of resveratrol. It was found that the highest extraction of resveratrol was achieved using ethanol-water (80:20 v/v \%).

Several studies stated that resveratrol is present in all part of the grapevine, including grapes and can therefore be extracted to produce a high value product (Aaviksaar et al., 2003; Soural et al., 2015; Averilla et al., 2019). Wine industries in South Africa produce large quantities of solid waste (SA wine industry 2018 statistics, 2019). The solid winery waste could be used as a resveratrol source. It was observed from the literature that factors that affect resveratrol production are under researched and the distribution of resveratrol in different parts of the grapevine and the variability of resveratrol between harvests is unknown. This paper aims to determine the distribution of resveratrol and other phenolics in the different parts of Pinotage solid waste over consecutive harvests.

\section{MATERIALS AND METHODS Samples}

Grape berry bunches, canes (shoots) and leaves of Pinotage were collected from a single vine, during March of the 2018 and 2019 harvest from the Welgevallen Experimental farm. Analytical standard resveratrol $(\geq 99 \%), 2$ molar FolinCiocalteu phenol reagent, gallic acid, anhydrous sodium carbonate $(\geq 99.5 \%)$ and methanol $(\geq 99.6 \%)$ were purchased from Sigma-Aldrich (Germany) and absolute ethanol was obtained from Kimix chemicals (South Africa).

\section{Resveratrol}

The resveratrol in each solvent sample was quantified using 
an in-house developed method on High-Performance Liquid Chromatograph (HPLC) on a Dionex Ultimate 3000 system with UV detection at $306 \mathrm{~nm} .100 \mu \mathrm{L}$ samples were analysed on a Phenomenex Jupiter C18 column (4.6 x $250 \mathrm{~mm}$ ) at $30^{\circ} \mathrm{C}$. The column was eluted with water and $5 \mathrm{mM}$ trifluoroacetic acid as the mobile phase A and acetonitrile with $5 \mathrm{mM}$ trifluoroacetic acid as mobile phase B over a $20 \%$ - $100 \%$ acetonitrile gradient. The run time was 112 minutes and the retention time was 64 minutes. The limit of detection was $0.006 \mathrm{mg} / \mathrm{L}$ and limit of quantification was $0.109 \mathrm{mg} / \mathrm{L}$. The quantitation was through external calibration with transResveratrol standard from Sigma. Identification through comparison with peak retention time and spectra versus standard.

\section{Total polyphenols}

Folin-Ciocalteu (FC) is a colorimetric assay that was used to determine the phenolic content of the different biomass samples (Ainsworth \& Gillespie, 2007). Each of the samples were diluted to make up a volume of $100 \mu \mathrm{L}$. Each $100 \mu \mathrm{L}$ sample was mixed with $200 \mu \mathrm{L}$ of $10 \mathrm{v} / \mathrm{v} \%$ Folin-Ciocalteu reagent for 30 seconds using a vortex mixer. After 30 seconds of mixing mixing, $800 \mu \mathrm{L}$ of $0.7 \mathrm{M} \mathrm{Na} 2 \mathrm{CO} 3$ solution was added and vortexed again. The samples were stored for 2 hours at ambient temperature. $200 \mu \mathrm{L}$ of each sample was transferred to a 96-well microplate to be analysed using a BioTek Elx800 spectrophotometer. The absorbance of each sample was converted to concentration in terms of gallic acid equivalent (GAE) with a gallic acid standard curve.

\section{Extraction}

From the comparison of the different solvents by (RomeroPérez et al., 2001), the 80:20 v/v \% ethanol-water mixture extracted the highest concentration resveratrol and hence was used for resveratrol extraction from different parts of a Pinotage vine. To account for the environmental factors that affect resveratrol production and to investigate resveratrol distribution throughout a single plant, grape bunches, canes and leaves were collected from the same vine. After harvesting, a portion of the collected grapes were fermented for 10 days using wild yeast. After the first fermentation step, the skins and seeds, called the pomace, were pressed and removed. The skins and seeds were separated, dried at $50^{\circ} \mathrm{C}$ and homogenised for two minutes using a $1700 \mathrm{~W}$ Nutribullet. The canes were dried and milled using a hammer mill. The milled canes were also homogenised to a fine powder using a $1700 \mathrm{~W}$ Nutribullet for two minutes. The sourced leaves and stems were dried until all the moisture was removed and homogenised for two minutes.

The dried pre-fermentation skins and seeds, postfermentation skins and seeds, canes, stems and leaves were each mixed in a 1:10 solid to solvent ratio and mixed for 24 hours at ambient temperature in $50 \mathrm{~mL}$ falcon tubes at $50 \mathrm{rpm}$, using a rotary sample mixer. A samples for each component taken after one, four, seven and twenty-four hours. The extracted samples were filtered with $0.2 \mu \mathrm{m}$ PES syringe filters for HPLC and FC analysis. From the HPLC analysis. The resveratrol concentration in each sample was determined, while the FC method using spectroscopy (UVvis) was used to determine the total phenolic content.

\section{RESULTS AND DISCUSSION}

\section{Resveratrol}

Resveratrol is a phytoalexin produced by Vitis vinifera as a response to biotic and abiotic stresses. Several studies have reported that resveratrol concentrations are dependent on factors such as terroir, geography, grape variety, parts of the vine, vinification process, and fungal infestation (RomeroPérez et al., 2001; Vincenzi et al., 2013). To investigate the resveratrol distribution in different parts of the vine, and the variability of resveratrol content from one year to the next, samples from the same grapevine were collected and analysed during the 2018 and 2019 vintage.

The resveratrol concentration in the pomace (skins and seeds), stems, canes and leaves were determined (Figs. 2 and 3). The resveratrol concentration varied within the different parts of the vine, with the canes and stems having the highest resveratrol concentration, i.e. $7.5 \pm 3.6 \mu \mathrm{g} / \mathrm{g}$ and $5.4 \pm 2.3$ $\mu \mathrm{g} / \mathrm{g}$, respectively (Fig. 2). A maximum of $0.8 \mu \mathrm{g} / \mathrm{g}$ and $0.7 \mu \mathrm{g} / \mathrm{g}$ resveratrol was extracted from the leaves and postfermentation skins. Resveratrol could not be extracted from the post-fermentation seeds using 80:20 v/v \% ethanol-water mixture.

According to Langcake \& Pryce, (1976) Vitis vinifera (Cabernet Sauvignon) leaves can contain between $50 \mu \mathrm{g} / \mathrm{g}$ to $400 \mu \mathrm{g} / \mathrm{g}$ resveratrol. When comparing the resveratrol extracted from the leaves to the study of Langcake \& Pryce, (1976), it was found that the resveratrol concentration was lower, confirming that it is dependent on factors such as geography and grape variety. Even though the resveratrol concentration reported in this paper was lower than expected, the results correspond to the work of (Lachman et al., 2016). According to Lachman et al., (2016), grape canes have the highest resveratrol concentration, i.e. $9.26 \pm 1.53 \mu \mathrm{g} / \mathrm{g}$, followed by the stems and leaves, each containing $1.76 \pm$ $0.51 \mu \mathrm{g} / \mathrm{g}$ and $0.51 \pm 0.33 \mu \mathrm{g} / \mathrm{g}$ resveratrol.

In order to determine if resveratrol concentrations vary between vintages, grape berries, stems, leaves and canes from the same grapevine were collected and analysed to investigate possible resveratrol variation.

The resveratrol concentration varied within the 2019 vintage (Fig. 3). From the HPLC analysis it was found that the maximum concentration of $73 \pm 4.3 \mu \mathrm{g} / \mathrm{g}$ resveratrol was extracted from the stems. The resveratrol extracted from the canes varied from $12 \pm 6.4 \mu \mathrm{g} / \mathrm{g}$ to $14 \pm 8.1 \mu \mathrm{g} / \mathrm{g}$. No resveratrol was extracted from the 2019 harvest leaves, post-fermentation skins and seeds. From the comparison of the resveratrol concentration in the leaves, skins and seeds from the 2018 and 2019 harvest, the data suggest that more resveratrol solubilized during the 2019 fermentation. To determine the resveratrol concentration that solubilized during fermentation, the pre-fermentation skins and seeds were extracted and analyzed. From the analysis of the prefermentation skins and seeds extracts, it was found that resveratrol levels were below detectable limits of the HPLC with the method used. It was concluded that the Pinotage skins and seeds extracts contained resveratrol below the $0.006 \mathrm{mg} / \mathrm{L}$ resveratrol detection limit. As a comparison, Shiraz and Grenache skins were also dried, homogenised, extracted and analysed the same as the Pinotage biomass samples and it was found the Shiraz and Grenache contained 


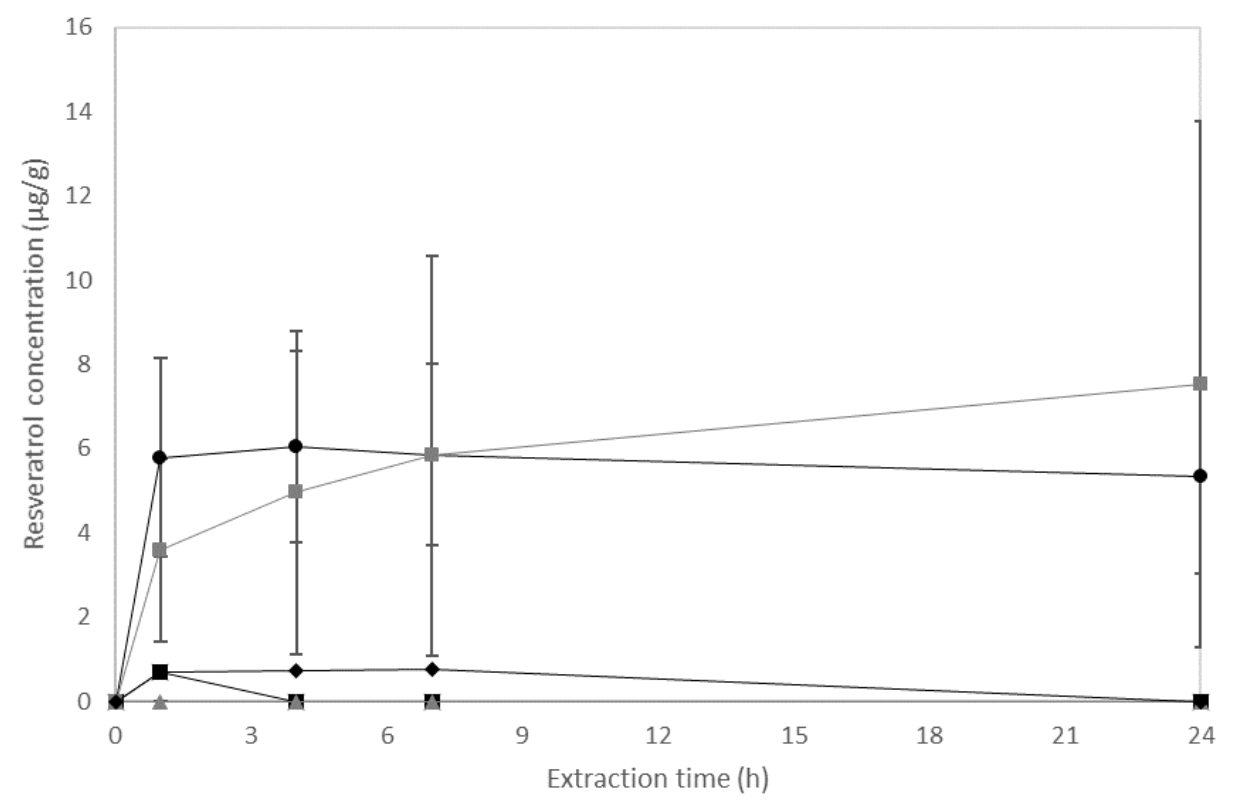

FIGURE 2

Mean resveratrol content of triplicate samples ( $\mu \mathrm{g}$ resveratrol/ $\mathrm{g}$ dried biomass \pm standard error) extracted from the 2018 Pinotage canes ( $\bullet$ ) and stems $(\bullet$ ) over 24 hours with $80 \%$ ethanol under ambient conditions. Mean resveratrol concentration of duplicate samples ( $\mu \mathrm{g}$ resveratrol/g dried biomass) of the 2018 Pinotage post fermentation skins ( $\mathbf{\square})$, post fermentation seeds

$(\Delta)$ and leaves ( $\bullet$ extracted with $80 \%$ ethanol.

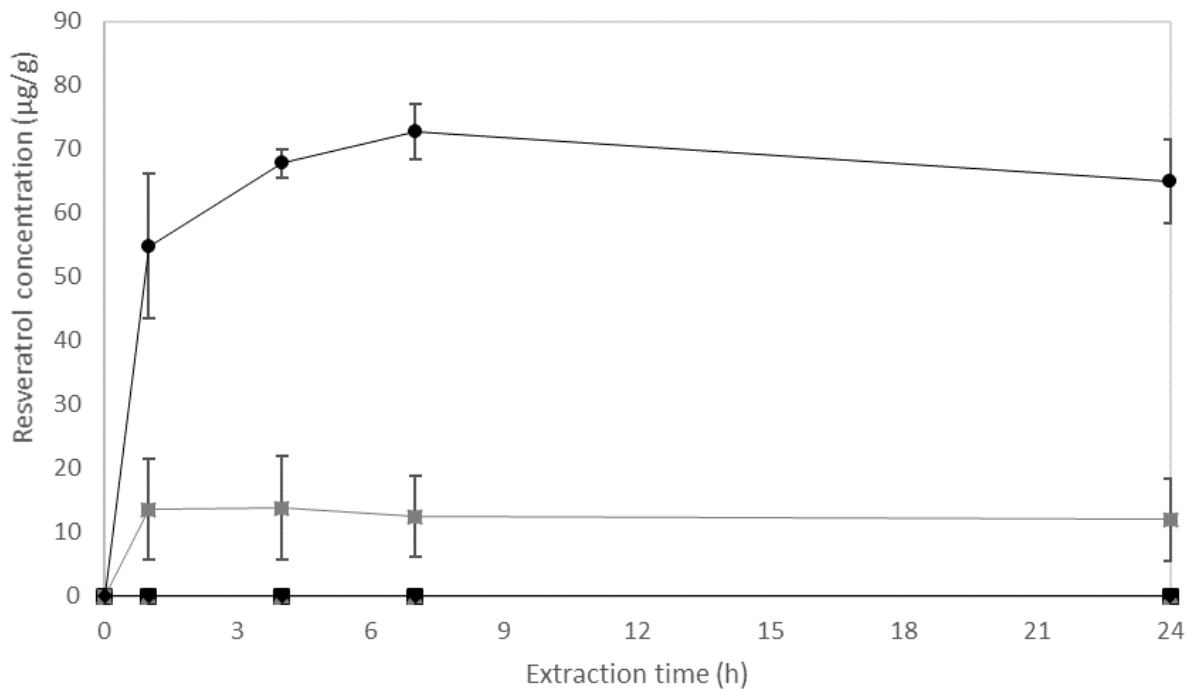

FIGURE 3

Mean resveratrol content of triplicate samples ( $\mu \mathrm{g}$ resveratrol/ $\mathrm{g}$ dried biomass \pm standard error) extracted from the 2019 Pinotage canes $(\boldsymbol{\bullet})$, stems $(\bullet)$, post fermentation skins $(\bullet)$ and seeds $(\boldsymbol{\Delta})$ and leaves $(\bullet)$ over 24 hours with $80 \%$ ethanol under ambient conditions.

$5.8 \pm 0.52 \mu \mathrm{g} / \mathrm{g}$ and $45 \pm 2.2 \mu \mathrm{g} / \mathrm{g}$ resveratrol, respectively. Confirming that resveratrol concentrations vary according to grape variety. By comparing the extracted resveratrol concentration from the canes and stems, it was found that the resveratrol concentration varied over time even in the same grapevine. This is the first time this result is reported, and has significant implications for the industrial harvesting of resveratrol from vine biomass.
By comparing the extracted resveratrol concentration from the canes and seeds, it was found that the resveratrol concentration varied between harvests, even in the same vine. It is reported in the literature that resveratrol concentration varies not only within different regions but also between different grape varieties (Geana et al., 2015), however, this is the first demonstration of significant resveratrol concentration variation within the same vine in consecutive 
harvests. The implications for harvesting biomass for resveratrol recovery are considerable - it may be necessary to conduct yearly resveratrol quantification, rather than assume similar productivities between years.

It should be noted that the Pinotage grapevine tested was not infected with Botrytis cinerea nor Plasmopara viticola. Most literature argues that biotic stresses are the primary cause of resveratrol production (Table 1), however, the only mildly different environmental conditions between these two harvests gave rise to significant year-on-year differences in resveratrol concentrations. The average Stellenbosch weather conditions from pruning to harvesting are summarised in Table 1, to compare the 2018 and 2019 growth conditions (WorldWeatherOnline, 2012).

Clearly, many factors influence resveratrol productivity, and the industrialist intent on recovering resveratrol from waste biomass cannot rely on previous years' concentrations as indications of subsequent harvests' concentrations.

The canes and stems contained more resveratrol, compared to the skins, seeds and leaves. The canes and stems, for the most part, are underutilized biomass, and may prove to be a useful source of phenolics and resveratrol. According to Devesa-Rey et al., (2011), cane trimmings can be valorized into several products (Fig. 1), but is mostly used as mulch, while the stems are used as for compost or are incinerated.

\section{Total phenolic content}

According to the literature, total phenolic content as a proxy for resveratrol content is commonly used. In order to verify this correlation, the total phenolic content of the different Pinotage extracts was determined with the FC assay. The total phenolic content of the skins, seeds, stems, canes and leaves from the 2018 and 2019 were determined in terms of gallic acid equivalents (Figs. 4 and 5).

From the comparison (Figs 4 and 5) of the total phenolic content in the different 2018 samples it was found that the leaves had the highest overall total phenolic content with a maximum of $5.02 \pm 0.16 \mathrm{mg} / \mathrm{g}$. The phenolic content in the post-fermentation skins ranged from $3.98 \pm 0.081$ $\mathrm{mg} / \mathrm{g}$ to $4.22 \pm 0.10 \mathrm{mg} / \mathrm{g}$ and from $1.07 \pm 0.013 \mathrm{mg} / \mathrm{g}$ to $1.4 \pm 0.11 \mathrm{mg} / \mathrm{g}$ in the cane trimmings. By comparing the resveratrol concentration to the total phenolic content of the 2018 Pinotage, it was concluded that there is no correlation. The canes had the highest resveratrol concentration but the lowest total phenolic content, while the skins, leaves and seeds had the lowest resveratrol concentration. The 2019
Pinotage extracts were also analysed with FC to determine the total phenolic content. The total phenolic content of the stems, leaves, post-fermentation skins and seeds were within similar range, while the canes contained up to $2.36 \pm 0.22 \mathrm{mg}$ phenolics per gram of dried canes.

It was found that from the 2018 to 2019 harvest, the total phenolic concentration remained between 4 to $5 \mathrm{mg}$ gallic acid per gram of dried skins, seeds, stems and leaves. While the average phenolic concentration in the cane trimmings increased from $1.22 \pm 0.06 \mathrm{mg} / \mathrm{g}$ to $1.95 \pm$ $0.22 \mathrm{mg} / \mathrm{g}$ from 2018 to 2019. By comparing the phenolic and resveratrol concentration it was concluded that there was no correlation between the total phenolic content and resveratrol, a somewhat surprising result, and one which rules out the use of phenolic concentration as a short-hand for resveratrol concentration as is often used in the literature. The distribution of phenolic compounds is dependent on the part of the vine (Xia et al., 2013). Phenolics such as gallic acid, epicatechin, catechin, quercetin, myricetin, ellagic acid and resveratrol are present in different concentrations and ratios in the different parts of the vine (Xia et al., 2013), confirming that total phenolic content cannot be used as a proxy for resveratrol.

During the fermentation some of the phenolic compounds solubilized from the skins and seeds into the must. To determine the degree of solubilisation, the total phenolic content in the pre- and post-fermentation of Pinotage skins and seeds were determined and compared. Approximately $610 \mathrm{mg}$ and $130 \mathrm{mg}$ phenolics solubilised per kilogram of dried grape skins and seeds respectively. Since limited information about resveratrol distribution in Pinotage biomass is available, the phenolic content was compared to a study of the phenolics present in South African Pinotage wine by De Beer, (2002). According to (De Beer, 2002), the average phenolic concentration in Pinotage is $625 \mathrm{mg} / \mathrm{kg}$, assuming $1 \mathrm{~kg}$ of grapes are used per $750 \mathrm{~mL}$ wine. By comparing the concentration of phenols that solubilized during the fermentation process to the total phenolic content in Pinotage wine as determined by De Beer, (2002), it was found that the phenolic concentration was similar.

\section{CONCLUSIONS}

The aim of the research was to determine the resveratrol and total phenolic content in different parts of solid winery waste, comparing a 2018 and 2019 Pinotage harvest. From the comparison of the average resveratrol and phenolic compound concentration from 2018 and 2019 seasons, it

TABLE 1

Comparison of the average climatic conditions during the 2018 and 2019 vintage and harvest period in Stellenbosch (World Weather Online, 2019).

\begin{tabular}{|c|c|c|c|c|}
\hline & Rainfall (mm) & Temperature $\left({ }^{\circ} \mathrm{C}\right)$ & Humidity (\%) & UV index \\
\hline 2018 Harvest & 463 & $\begin{array}{c}15.8 \\
\text { Min. } 1 \\
\text { Max. } 36\end{array}$ & 67.7 & 4.67 \\
\hline 2019 Harvest & 685 & $\begin{array}{c}17.8 \\
\text { Min. } 1 \\
\text { Max. } 36\end{array}$ & 66.4 & 5.08 \\
\hline
\end{tabular}




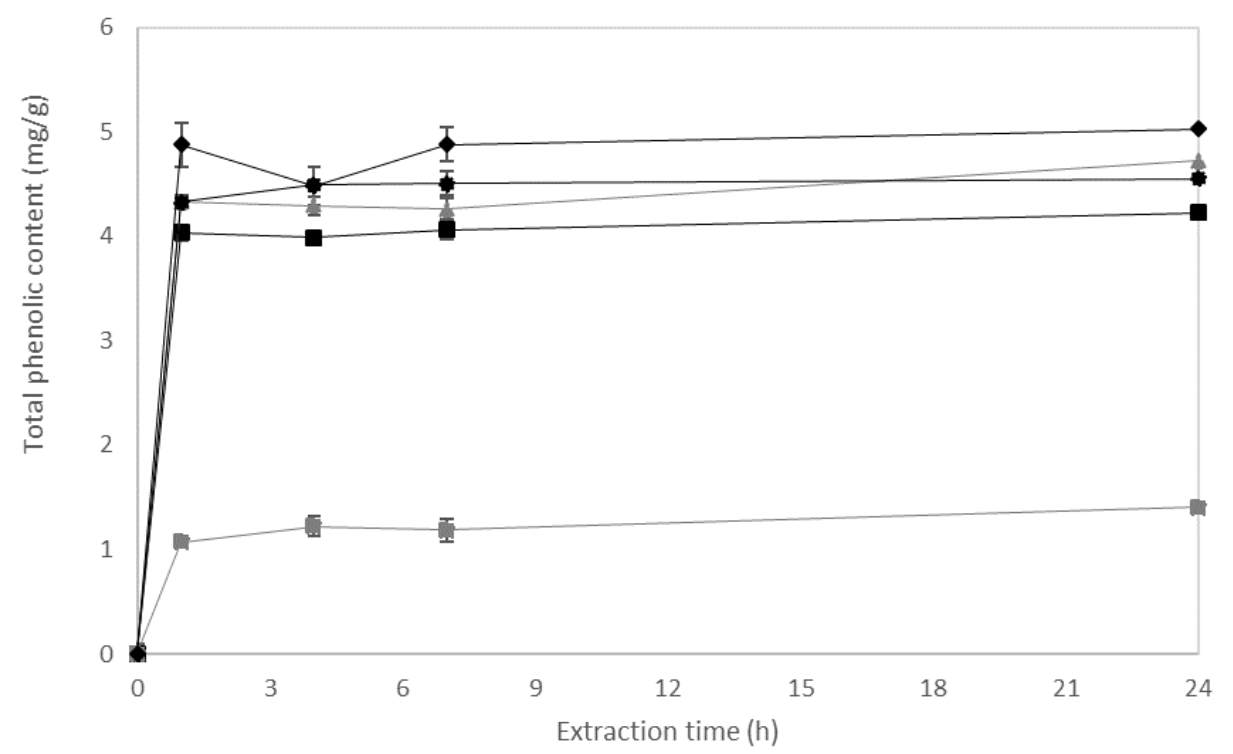

FIGURE 4

Mean total phenolic content of triplicate samples ( $\mu \mathrm{g}$ resveratrol/ $\mathrm{g}$ dried biomass \pm standard error) extracted from the 2018 Pinotage canes $(\boldsymbol{\bullet})$, stems $(\bullet)$, post fermentation skins $(\boldsymbol{\bullet})$ and seeds $(\boldsymbol{\Delta})$ and leaves $(\bullet)$ over 24 hours with $80 \%$ ethanol under ambient conditions.

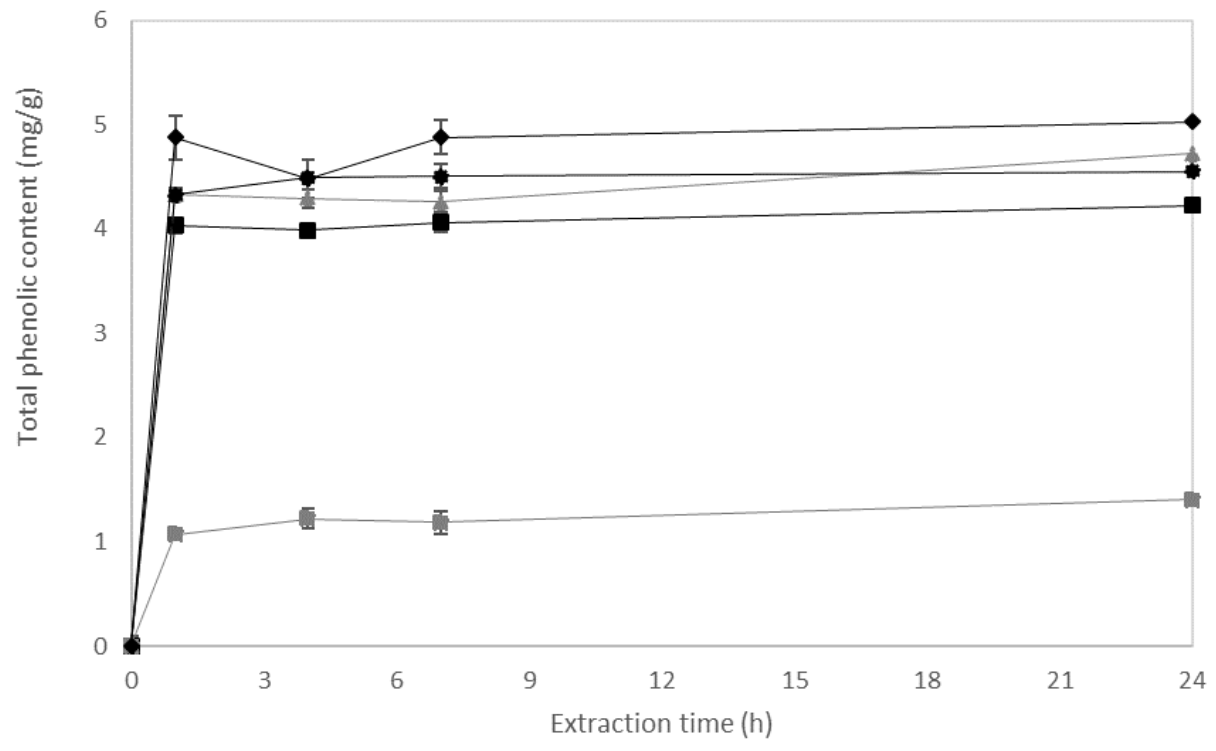

FIGURE 5

Mean total phenolic content of triplicate samples ( $\mu \mathrm{g}$ resveratrol/ $\mathrm{g}$ dried biomass \pm standard error) extracted from the 2019 Pinotage canes $(\boldsymbol{\bullet})$, stems $(\bullet)$, post fermentation skins $(\boldsymbol{\bullet})$ and seeds $(\boldsymbol{\Delta})$ and leaves $(\diamond)$ over 24 hours with $80 \%$ ethanol under ambient conditions.

was concluded that variability in resveratrol concentration exists within the vine as well as over time. This variability in resveratrol productivity would affect the biomass feed stream and thus any large scale production process.

The total phenolic content of the different parts of the waste of the consecutive harvests were extracted to determine if there is a correlation between the total phenolic content and resveratrol. It was observed that there is no correlation between the resveratrol concentration and the total phenolic content.
In terms of which biomass has the greatest resveratrol concentration, in both years the stems and canes showed significant concentrations $(5.4 \pm 2.3 \mu \mathrm{g} / \mathrm{g}$ and $7.5 \pm 3.6 \mu \mathrm{g} / \mathrm{g}$, respectively, in the 2018 harvest) while the leaves had very low concentrations.

Since the grape stems and canes are not currently being valorized, the high resveratrol concentration that is present in these biomasses can be utilised as a possible resveratrolantioxidant supplement source. 


\section{LITERATURE CITED}

Aaviksaar, A., Haga, M., Püssa, T., Roasto, M. \& Tsoupras, G., 2003. Purification of resveratrol from vine stems Proc. Est. Acad. Sci. Chem 52 $155-164$

Ainsworth, E.A. \& Gillespie, K.M., 2007. Estimation of total phenolic content and other oxidation substrates in plant tissues using Folin-Ciocalteu reagent Nat. Protoc. 2, 4, 875-877.

Averilla, J.N., Oh, J., Wu, Z., Liu, K., Jang, C.H., Kim, H.J., Kim, J. \& Kim, J., 2019. Improved extraction of resveratrol and antioxidants from grape peel using heat and enzymatic treatments J. Sci. Food Agric. 99, 8, 4043-4053.

De Beer, D., 2002. The Antioxidant Activity of South African Wines in Different Test Systems As Affected By Cultivar and Ageing Stellenbosch University.

Beres, C., Costa, G.N.S., Cabezudo, I., da Silva-James, N.K., Teles, A.S.C., Cruz, A.P.G., Mellinger-Silva, C., Tonon, R. V., Cabral, L.M.C. \& Freitas, S.P., 2017. Towards integral utilization of grape pomace from winemaking process: A review Waste Manag. 68, 581-594.

Devesa-Rey, R., Vecino, X., Varela-Alende, J.L., Barral, M.T., Cruz, J.M \& Moldes, A.B., 2011. Valorization of winery waste vs. the costs of not recycling Waste Manag. 31, 11, 2327-2335.

Geana, E.I., Dinca, O.R., Ionete, R.E., Artem, V. \& Niculescu, V.C., 2015 Monitoring trans-resveratrol in grape berry skins during ripening and in corresponding wines by HPLC Food Technol. Biotechnol. 53, 1, 73-80.

Karacabey, E. \& Mazza, G., 2008. Optimization of Solid-Liquid Extraction of Resveratrol and Other Phenolic Compounds from Milled Grape Canes ( Vitis vinifera ) J. Agric. Food Chem. 56, 15, 6318-6325.

Lachman, J., Kotíková, Z., Hejtmánková, A., Pivec, V., Pšeničnaja, O., Šulc, M., Střalková, R. \& Dědina, M., 2016. Resveratrol and piceid isomers concentrations in grapevine shoots, leaves, and tendrils Hortic. Sci. 43, 25-32.
Langcake, P. \& Pryce, R.J., 1976. The production of resveratrol by Vitis vinifera and other members of the Vitaceae as a response to infection or injury Physiol. Plant Pathol. 9, 1, 77-86.

Marais, J., 2003. Literature Overview Of Pinotage Research, Wine Land Wineland.

Pezet, R. \& Cuenat, P., 1996. Resveratrol in Wine: Extraction From Skin During Fermentation and Post-fermentation Standing of Must From Gamay Grapes Am. J. Enol. Vitic. 47, 3, 287-290.

Roca, P., 2019. 2019 Statistical Report on World Vitiviniculture.

Romero-Pérez, A.I., Lamuela-Raventós, R.M., Andrés-Lacueva, C. \& de La Torre-Boronat, M.C., 2001. Method for the quantitative extraction of resveratrol and piceid isomers in grape berry skins. Effect of powdery mildew on the stilbene content. J. Agric. Food Chem. 49, 1, 210-5.

SA wine industry 2018 statistics, 2019. Paarl.

Soural, I., Vrchotová, N., Tříska, J., Balík, J., Horník, Š., Cuřínová, P. \& Sýkora, J., 2015. Various Extraction Methods for Obtaining Stilbenes from Grape Cane of Vitis vinifera L. Molecules 20, 4, 6093-6112.

Vincenzi, S., Tomasi, D., Gaiotti, F., Lovat, L., Giacosa, S., Torchio, F., Río Segade, S. \& Rolle, L., 2013. Comparative Study of the Resveratrol Content of Twenty-one Italian Red Grape Varieties South African J. Enol. Vitic. Vol 34, No 1 (2013)DO - 10.21548/34-1-1078 (November, 1).

WorldWeatherOnline, 2012. World Weather Online Available at http://www. worldweatheronline.com/Wageningen-weather/Gelderland/NL.aspx.

Xia, E., He, X., Li, H., Wu, S., Li, S. \& Deng, G., 2013. Biological Activities of Polyphenols from Grapes In: Polyphenols Hum. Heal. Dis Vol. 1. Elsevier Inc. 47-58. 